\title{
Miller, C. R. \& Kelly, A. R. (Ed.). (2017). Emerging genres in new media environments. Palgrave Macmillan/ Springer.
}

Tania S. Smith

University of Calgary

I took up this gem of an anthology in 2020, when genres were fluctuating and hold even more sway than ever in new media environments, at a time when face-to-face communication media are thinning out with social restrictions and facial barriers. Emerging in 2017, four years after the initial 2013 symposium spawned a call for chapters, Miller and Kelly's edited collection offers insight into how genres are continuing to engage with three dimensions: 1. medium, 2. transformation, and 3. values. "Values are manifested in and reproduced by genres, even as they may enable or provoke genre transformation," (vi) writes Miller in her editorial preface. What we value the most in and through our social interactions can be preserved and transformed by the way we communicate in new media. We are participating in reinscription, but also in change, in emergence.

\section{Miller's introduction}

Miller's introductory chapter focuses on the concept of genre "emergence," a useful metaphorical concept that has made its way through science and philosophy into rhetorical genre theory.

Miller's distinction between ontological and epistemological emergence is fruitful because we do not have the luxury of creating from utterly new material as genres emerge. There is an old joke named by its punchline, "Get your own dirt," about a scientist and God having a discussion regarding who can create new life. The joke has gone through several emerging genres and has many different versions online. Here it is in the form of a blog post by a Mennonite pastor Harold N. Miller, on a Christian blog from 2013:

A scientist says to God, "Lord, we don't need you anymore. Science has figured out a way to create life out of nothing. In other words, we can now do what you did in the beginning." "Oh, is that so? Tell me more," replies God.

"Well," says the scientist, "we can take dirt and form it and breathe life into it." 
Volume 30, 2020

http://journals.sfu.ca/cjsdw

"Well, that's interesting. Show Me."

So the scientist bends down to the earth and starts to mold the soil.

“Oh, no, no," interrupts God. “Get your own dirt.” (para. 1)

Like the scientist (in some versions, it's a group of scientists), we can't easily get our own dirt, our own ontology, the things that were and are, the things that we already know together. We can only work with what emerges from our given "dirt," how we continue to do knowledge together, and "phenomenological" emergence: how we experientially genre it together.

Miller lays the concept of genre "evolution" on top of emergence, making it less deterministic and less about stabilization of species than it may seem. She says that as we genre scholars track and observe new generic variants, "we are seeking not the stabilization of these variants but rather the stabilization of shared recognitions and social agreements" (p. 5), and these are only temporary stabilizations in the way we use the genres, the phenomenology of evolving genres. She invokes Todorov's question of origins, "From where do genres come?" and the answer is "Why, quite simply, from other genres" (p. 7). As dirt and matter provides material to recombine, life begets new life, and genres (in the plural, not singular) beget new genres. Miller quotes Fowler: "in literature there is no creation ex nihilo" (p. 7). The work of the genre scholar is then to "map out" (p. 8) the expanding landscape of genres, and to engage in "tracking and tracing variants" (p. 5) populating the map, understanding the mechanisms of their emergence.

Miller offers her own useful scholarly map, a numbered list of genre types by domain:

1. Marketed/Commercial,

2. Administered,

3. Institutional, and

4. Vernacular (p. 23-25).

Her taxonomy is appropriately filled with verbs of social action regarding the ways that they emerge from social networks of power that provide constraints, evoke desires, and fulfill the desires of those that regulate, make and consume them.

With this deeply thought-provoking introduction as equipment for the journey, I entered the landscape of chapters in the three sections. Here, I only have space to feature a few selected landmarks of my own reading journey to help you map out your own. 
Volume 30, 2020

http://journals.sfu.ca/cjsdw

\section{Part 1: Medium}

This part of the book offers five chapters spanning themes of technological change, health narratives, Twitter versus YouTube, user interfaces, and game genres. Janet Giltrow first offers examples from photographs to news comments to illustrate the ways that genres bridge primary conversational genres to secondary mediated genres. A major insight is that the bridging genres often take on the names of the uses of technologies, such as "blogging." Next, Lora Aduser examines illness narratives in video blogs (vlogs) and finds that YouTube helps to enculcurate new vloggers to the medium as well as ways of using it. Natalia Rulyova's chapter profiles the way everyday technology users published their recordings of a meteor explosion in Chelyabinsk, Russia. She points out that the hashtag "meteorite" collected a smorgasbord of genres based on primary media devices like dashboard camera recordings as well as secondary media such as Twitter jokes. Media users' "global genres" (p. 93) were customized to their local Russian context. Ben McCorkle's chapter on "natural" user interfaces (NUIs) begins by explaining the way he signs into his smartphone via a facial scan. His historical sweep from writing technology to the NUI directs attention to the ways the assumptions about "natural" gesture, voice, and touch mean certain bodies may not be granted easy access to NUIs that create genres, and more often gain access to NUIs that enable their consumption. Finally, Brad Mehlenbacher and Christopher Kampe explore pedagogical uses of gaming by profiling a game called This War of Mine, offering a practical suggestion to educators to view their use of the genre as "expansive play" within an activity system (p. 124): we can productively attend to the circumstances and social actions of the communicative work surrounding a game, rather than focus on a game's internal features.

\section{Part 2: Genre transformation}

This part of the volume offers four chapters exploring printed to digital newspapers, HIV/AIDS narratives, videogame adaptations, and Amazon.com. Jacqueline Barreto Lé opens with Bonini's concept of the newspaper as "hypergenre" (p. 137) that collates many other genres. By comparing the genres of the print with the digital newspaper, she discovers different modes of interactivity, linearity shifted to nonlinearity, and multimodality moved into hypermodality, which "offers a space for new practices and social actions" for journalism and its publics (p. 145), and an increase in information velocity. Huiling Ding, in a chapter on a large corpus of online HIV/AIDS narratives, provides a useful taxonomy of seven informative moves, four interactive moves, and two emotional 
Volume 30, 2020

http://journals.sfu.ca/cjsdw

moves, some with substeps within them. An understanding of these moves within such "intermediary genres" (p. 166) may assist public health communicators. In the second chapter of the book on the topic of gaming, Neil Randall focuses his chapter on gaming adaptations on Turbine's Lord of the Rings Online (LOTRO) game and explores its tenuous relationship to the Peter Jackson films and the original Tolkien collection. Randall reveals that the paratextual relationship between the gaming adaptation and its source does not overrule the gaming experience in which people interact through common massively multiplayer online game (MMO) conventions and usability features. Next, Christopher Basgier plays with the concept of "genre defiance," breaking generic rules (p. 189), in his chapter on the Amazon.com review genre. Basgier employs Hesse's ideas to show that "market exigenc[ies]" do not overtake the project of "self-fashioning" by reviewers (p. 190-191). Readers of reviews may relish their creative use of irony and metaphor that respect Amazon.com review guidelines even while satirizing the assumptions behind the products for sale.

\section{Part 3: Values}

This final section of the book offers a final six chapters delving into "autopathographies" (experiences of illness; treatment, and/or death); deliberation about immigration; public commemoration; "textual tactility" and verisimilitude; feminist histories of rhetoric; and a postscript on the futures for genre studies. Tamar Tembeck reprises several earlier chapters' themes of illness narratives, yet this chapter reflects on two posthumous interactive multimedia artworks and explains how they can offer seemingly limitless archives of personal diaries with which (or with whom) we can converse. Next, E. Johanna Hartelius proposes that a genre of sentimentalism has taken over media discourses of immigration to the United States, pushing deliberative genres into an epideictic mode. She illustrates this phenomenon in video narratives by members of a university and academic institute. Victoria J. Gallagher and Jason Kalin engage in analysis of the Auschwitz-Birkenau Memorial and Museum. They ponder how its renewal as a physical museum space can productively engage in contesting authentic memory, prompting "useful collective action in the present" (p. 244), rather than being "mere entertainment" (p. 245). The following chapter by Colbey Emmerson Reid poses questions about the oft-prophesied death of the medium of the physical book and the anxieties this causes for some; the essay explores how digital books can mimic the tactile experience virtually by means of touch interfaces.

Risa Appelgarth's chapter at the end of part 3 is close to my own heart as a rhetorical historian. How does gender play a role in "short-lived, discarded, and non-dominant genres" (p. 276) by 
Volume 30, 2020

http://journals.sfu.ca/cjsdw

marginal community members? As archaeologists, rather than evolutionary biologists, rhetorical historians can provide exempla from the past that can be applied to critique power in new media genres. To provide her own series of exempla, Appelgarth grapples with the discipline of archaeology itself and names scholarly women and professionals of color whose marginal monograph genres were discarded in favor of larger names and modes with a higher uptake, as signified by citation. The chapter made me consider my own interest in excavating the valued yet forgotten works of eighteenth-century rhetors, such as translators and women, whose rhetorical labors deserve to have delayed impact on our own era. It made me wonder how new media could become a platform to disseminate these artifacts to contemporary publics in conversational, layered genres.

\section{Kelly's postscript}

Co-editor Ashley R. Kelly's postscript, "Futures for Genre Studies," ties together some of the themes of the edited collection and then reflects on the field's growth across the disciplines and globally. Kelly suggests that the idea of genre is moving "toward a complicated and likely contested idea of human communication in all its linguistic, social, and cognitive capacities" (p. 293). The chapter briefly encapsulates descriptions of the field's activities and aims, which are intertwined with Miller's original goal, 32 years ago, of defining genre in a "rhetorically sound" way (p. 294).

\section{Conclusions}

Overall, this is a fine collection of chapters, well unified and edited by Miller and Kelly, that deserves to be penciled on and earmarked, then cited and built upon, in forthcoming scholarly publications. I hope we take up the inspiring call of this book to inscribe our genre scholarship in transformative ways in new media, not just in traditional books and journals.

\section{References}

Miller, C. R. \& Kelly, A. R. (Ed.). (2017). Emerging genres in new media environments. Palgrave Macmillan/Springer.

Miller, H. N. (2013, September 17). Get your own dirt ... and laws. Simple truths in love and wonder. http://interactingwithjesus.org/blog/2013-09-17-2013-09-17-get-your-own-dirt-and-laws/ 